Luca Sandrini

DSEA, University of Padova

\title{
INNOVATION, COMPETITION AND INCOMPLETE ADOPTION OF A SUPERIOR TECHNOLOGY
}

May 2020

Marco Fanno Working Papers - 251 


\title{
Innovation, Competition and Incomplete
}

\section{Adoption of a Superior Technology}

\author{
Luca Sandrini \\ University of Padova, luca.sandrini.3@phd.unipd.it
}

January, 2019

\begin{abstract}
This article analyses the licensing choices of an outside inventor who owns a patent for a superior cost-saving technology. Moreover, I show that licensing via uniform upfront fees is found to be superior to licensing via royalties, from the inventor perspectives. This is so, regardless of the number of manufacturers in the product market, as downstream competition foster the inventor's incentives to develop a more effective cost-saving technology, raising his/her revenues from surplus extraction. Moreover, this article investigates the effect of competition on licensing outcomes and ex-post market concentration.
\end{abstract}

JEL Code: L13, L22, L24

Key-Words: Innovation, Licensing, Vertical Relation, Oligopoly, Competition 


\section{Introduction}

Innovation is a fundamental source of economic growth. For this reason, how to prompt the firms' incentives to invest in R\&D has always been among the most investigated topics in Industrial Organization and economic theory in general. In particular, a core issue is how to guarantee the innovators the rightful appropriation of the returns on investments in $\mathrm{R} \& \mathrm{D}$, in order to encourage them to keep investing and disclose their inventions. Today, the solution to this trade off between innovation's disclosure and appropriability is given by patents and intellectual property right laws. Once a patent is granted, the innovator is provided with a temporary monopoly on his/her invention, so that (s)he is able to disclose it with no risk of exploitation by free riding rivals. From the seminal work of Kenneth Arrow, we know that, when firms are able to appropriate the value generated by their investments in $R \& D$, perfect competition provides the highest incentives to innovate. This is so because firms want to escape the competitive pressure and leapfrog their rivals by becoming more efficient. However, market structure does not only affect incentives to invest in innovative activities. Once a new technology has been granted, a secondary issue emerges, that is the diffusion of such an innovation in the market. In this article, I further analyse the competition-innovation nexus by looking at how downstream market structure alters the incentives to invest in a cost saving technology of an outside innovator. I identify a direct positive effect of downstream competition on the size of innovation in equilibrium, and an indirect effect via the licensing outcome. Moreover, applying a linear Cournot model in a vertical market setting, I show that licensing via upfront fees is more profitable for the inventor than licensing via royalties, when the innovation is sufficiently large or very small. On the contrary, for intermediate level of innovation size, royalties yield larger profits to the monopolist inventor. As competition level affects both the manufacturers' incentives to adopt the innovative technology and the innovator's incentives to invest in its development, the choice of the contract and the rate of adoption are crucially 
affected by how many firms are competing in the product market.

Finally, I discuss some welfare implications of the licensing of an innovation via upfront fee. I show that competition in the product market disproportionally fosters the benefits of the innovator compared to those of consumers and manufacturers. This happens for two main reasons: first, when competition becomes more intense, the opportunity cost of adoption falls, raising the ability to extract the surplus by the innovator. Second, large innovations push the price of the final good down to the marginal cost of production associated with the rival technology. Thus, the more competitive the market, the less effective the innovation in lowering the market price, and the higher the adopters markups. From a policy-maker's perspective, however, the markups of adopting firms do not constitute an issues, as they do not lower Consumer Surplus and are mainly due to the change in the cost structure of the adopters, which shifts from a variable cost structure to a mixed one with a variable and a fixed component. ${ }^{1}$ Instead, the increase in market power experienced by the innovator may produce some concerns in the regulators, as it may be at odds with a ex-post pro-competitive behaviour. A proper analysis of the effects of such a distribution of the surplus generated by the introduction of a new technology goes beyond the scope of this article. Here, I suggest that market power accumulation by an outer innovator is a possible outcome of the introduction of a cost-reducing technology in a vertical market.

This paper is organized as follows: the rest of this section contextualizes this article in the literature. In section 2, I illustrate the model and the main assumptions.

\footnotetext{
${ }^{1}$ Indeed, this is a topical issue which is concerning policy-makers and researchers. In a recent study, IMF[2019] finds that, between 2000 and 2015, markups have increased in advanced economies. Apparently, the increase is more concentrated among a small fraction of innovative and productive firms. It must be said that, in this article, my focus is on margins rather than on actual markups - i.e. I consider the difference between product price and marginal cost of production.
} 


\subsection{Literature Review}

Katz and Shapiro [1985], Kamien and Tauman [1986, 1984], Kamien et al. [1992], Sen [2005], and Sen and Tauman [2007, 2019], among others, analyse the optimal licensing scheme confronting fixed fee licensing, royalty licensing, and licensing via auction. Generally, fixed fee and auction are found to be superior to licensing via royalty, although Sen [2005] and Sen and Tauman [2019] find conditions for royalties to yield larger patents' value. Also, they show that market outcomes are affected by the contractual form chosen by the innovator. In particular, fixed fee licensing drives the post-innovation price of the final good down and the consumer surplus up, making the firms worse off and consumers better off. Instead, licensing via royalty-based contracts does not alter the price of the final good, and allows the firms to earn at least the same amount of profits as in the pre-innovation scenario (see also Katz et al.[1990], Gallini and Wright [1990], Arora and Fosfuri [2003], and Hermosilla and $\mathrm{Wu}[2018]) .^{2}$ Furthermore, they show that perfect competition provides at least the same incentives as monopoly. Ertuku and Richelle [2007] find that it is always possible to design a two-part tariff contract scheme which ensures complete adoption of the superior technology and a level of profits for the inventor which replicate the monopoly profits of a manufacturers which is embedded with the superior technology. This article builds on these results on licensing and contributes by stressing the role of competition in determining both the optimal licensing contract (and therefore the equilibrium number of licensees) and the size of the innovation developed by the inventor. ${ }^{3}$ My contribution is to identify and sort the direct and indirect effects of competition on the innovation size and the value of the patent. Moreover, I show that as competition intensity has always a positive impact on the size of the cost-reducing effect, it also drives the choice of

\footnotetext{
${ }^{2}$ Lapan and Moschini [2000] show that licensing via royalty may lead to incomplete adoption of the superior technology if the innovation affects on the utilization, and therefore the price, of some other input used by the firms.

${ }^{3}$ See also Sen and Stamatopoulos[2016].
} 
the optimal contract type towards uniform upfront fees. In fact, this contract type allows the innovator a far better exploitation of the surplus increasing effect of the new technology and increases the value of the patent.

Vives[2008] and Beneito et al.[2015] provide theoretical and empirical support for opposite effects of competition on product and process innovations. According to the authors, high product substitutability and high costs of entry are associated with a higher amount of process innovations. Aghion et al. [2005] suggest that there is an inverted- $\mathrm{U}$ relation between competition and investments in innovation. This view synthesizes the two main theories on innovation and competition. On the one hand, there exists a monopoly advantage in fostering investments as the monopolist is able to collect high rents from his/her position; on the other hand, there is a replacement effect, or escape from competition effect, which is triggered by increasing competition. In a recent article, Marshall and Parra [2019] show that competition may affect innovation and Consumer Welfare in a non-obvious way, depending on the properties of the product market game (See also Parra [2019]). This article contributes to the literature by investigating the effect of competition in the product market on the profits of the innovator, the innovation's size, and the Social Welfare. I show that investments in $R \& D$ and the profits of the innovator are larger when competition is strong. Instead, competition reduces the effect of innovation on the Consumer surplus.

Berry et al. [2019] and Lamoreaux [2019] highlight the risks of market power accumulation and the concerns around the issue of increasing markups. In this article, I show that, although the rise of markups of adopting firms may be due to the fact that firms have to sustain a large fixed cost in order to be able to remain in business, the innovator's ability to "regulate" the market has some anti-competitive effects and obstacles full adoption of the superior technology.

Voudon [2019], Alipranti et al. [2015] and Milliou and Petrakis [2011], among others, investigate the connection between vertically related markets and innovation 
diffusion. However, they mainly focus on innovation by analysing the problem in a dynamic setting. As time proceeds, competition pushes the price of the innovation down and the rate of adoption increases; however, early adopters have some advantages and thereby a trade off emerges. Here, I do not focus on the timing of adoption. Instead, my goal is to show that the number of licensees that an outer patentee elicits is a negative function of product market competition and the innovator's efficiency. As above mentioned, this article deals with the issue of the exit of firms after the introduction of a new invention. Linking together market characteristics and firms' profitability, I show that the market structure and the strategic behaviour of the innovator and the producers help explain why some firms exit the market after the introduction of a new technology.

The results in this model are consistent with the "radical invention theory" in Jovanovic and McDonald [1994], according to the taxonomy in Klepper and Simons [2005] - although in a hardly comparable setting. According to the radical invention theory, a major invention generates a new market that immediately attracts many firms, which enter until the marginal profits fall to zero. Then, process innovations start lowering the costs of production for some firms and driving the inefficient ones out of business. This article sheds light on the moment when process innovations are introduced and start lowering the costs of production of the final good. A wide literature investigates the causes of post-innovation industry shake-outs (see Klepper [1996] and Geroski [1995] for a detailed analysis). However, this literature surveys the issue by following two main approaches: an event-based approach and an evolutionary one. Instead, I show that, since competition raises the licensing fee set by the inventor, it also prompts investments and increases the size of invention in equilibrium. When competition is sufficiently strong, the resulting innovation is large enough to generate an industry shake-out. 


\section{The model}

Consider an industry with $n$ identical firms (or manufacturers) that compete $\grave{a} l a$ Cournot for a homogeneous good and face a linear demand $P(Q)=a-b Q$, with $Q=\sum_{i=1}^{n} q_{i}$ being the total industry output. ${ }^{4}$ There are two technologies that can be used to produce the final good. The first one is a standard technology and represents the state of the art of the technological progress. It is freely available in the market and enables manufacturers to produce one unit of output at the cost $c$. Instead, the second technology is new and, if adopted, reduces the cost of producing a unit of output to $c-x$, with $x>0$ being the size of the innovation. The innovative technology is owned by a monopolist innovator (or supplier) who does not compete in the product market and is protected by a patent that prevents the replication by other agents. In order to develop the invention, the supplier invests $I(x)=\gamma x^{2}$, where $\gamma$ is a cost parameter. ${ }^{5}$ In order to license the new technology, the inventor sets either a royalty-based licensing scheme (with $r$ being the royalty rate) or an upfront fee $F$. For sake of simplicity, I will refer to downstream firms and to upstream innovator with the female pronoun "she" and the male pronoun "he", respectively.

Let us portion the manufacturers into two groups: I define $A$ as the set of firms that adopt the innovative technology, and $B$ as the set of firms that adopt the standard technology. Then, the objective function of the $i^{\text {th }}$ manufacturer can be written as:

$$
\pi_{i}= \begin{cases}(a-b Q-(c+r-x)) q_{i}+F(x) & \text { if } \quad i \in A \\ (a-b Q-c) q_{i} & \text { if } i \in B\end{cases}
$$

\footnotetext{
${ }^{4}$ The assumption of homogeneous products is adopted for sake of simplicity. In Appendix A.1, I show that, at least for the case of non-drastic innovations, the same results can be obtained if we assume firms produce different products.

${ }^{5}$ The parameter $\gamma$ adjusts the convexity of the R\&D cost function and it can be interpreted as the efficiency of the innovator. The lower $\gamma$ the less expensive it is to invest in the innovative technology.
} 
The inventor objective function is:

$$
\pi_{u}=\sum_{j=1}^{m} q_{j} r+m F(x)-I(x)
$$

where the subscript $u$ stands for upstream innovator, and $m \in[0, n]$ represents the number of manufacturers in $A$. Conversely, $n-m$ is the number of manufacturers in $B$.

Depending on the size of innovation $x$ and the number of adopters $m$, the innovation can be either non-drastic or k-drastic. In the first case, it does not alter the competition in the market (non-adopters are always able to produce positive quantities of the final good, as the market price of the final good never falls below the non-adopters' marginal cost of production). Instead, when the innovation is k-drastic - i.e., $x>(a-c) / k$ - the adoption of the new technology by at least $k$ manufacturers forces the non-adopters to exit the market as they are no longer able to produce any positive quantity with the standard technology. ${ }^{6}$ Thus, in this case, the innovative technology has an impact on the market structure and alters the post-innovation market concentration.

The timing of the game is as follows: at $t=0$ the monopolist innovator sets the size of the technology $x$; then, at $t=1$, he chooses which contract scheme to enforce (royalties vs upfront fee) and decides how many adopters $m$ to elicit. At $t=2$, the manufacturers choose which technology to adopt and compete in quantities. The game is solved by backward induction.

Notice that, as the number of adopters is a discrete variable, equilibrium in pure strategies may not exist due to discontinuity problems. Thus, in the following sections, I consider the number of adopters $m$ as a continuous variable. This assumption comes together with some carefulness in interpreting the results. Indeed, a more elegant way to deal with this issue would be to solve the equilibrium in mixed strategies. This would avoid any assumption on $m$. In Appendix A.3, I solve

\footnotetext{
${ }^{6}$ See Sen and Tauman [2007] for a formal definition of k-drastic innovations.
} 
the game following this last approach and show that the results are qualitatively robust. In what follows, I prefer to keep the procedure as simple as possible, as mixed strategies are not an obvious concept when we consider the investments of the firms.

\section{Results}

From eq. (1) we derive the Cournot output and profits of the manufacturers given the licensing contract type:

$$
\begin{gathered}
q^{A}=\frac{a-c+(n-m+1)(x-r)}{b(n+1)} \\
q^{B}=\frac{a-c-m(x-r)}{b(n+1)} \\
\pi^{A}=\frac{(a-c+(n-m+1)(x-r))^{2}}{b(n+1)^{2}}-F(x) \\
\pi^{B}=\frac{(a-c-m(x-r))^{2}}{b(n+1)^{2}}
\end{gathered}
$$

The manufacturers choose the technology knowing the contract type offered by the inventor. Moreover, the contract is either royalty-based or an upfront fee (I am not considering combinations of the two). Thus, whenever the royalty-based contract is offered, we have that $r>0$ and $F(x)=0$. Alternatively, if the innovator sets an uniform upfront fee $F(x)>0$, then $r=0$.

\subsection{Royalty-based licensing scheme}

Let us firstly consider the scenario with royalty based licensing contract. It is easy to show that the unique equilibrium royalty rate is $r=x$, regardless of the size of innovation (see Kamien and Tauman [2002], among others). In this case, the benefit from adopting the new technology is wiped out by the per unit expenditure 
that the manufacturer has to sustain in order to produce the output. Consequently, from eqs. (3) and (4) it is immediate to show that, as $q_{i}^{A}=q_{i}^{B}=\frac{a-c}{b(n+1)}$, and the firms are all indifferent between adopting or not the innovative technology. Let us assume as a tie-breaking rule that the manufacturers prefer the innovation, when it comes at no extra cost. Then, $m=n$ and all the firms choose to update their technological endowment. ${ }^{7}$ Starting from the downstream subgame, we can write the manufacturers output and profit functions:

$$
\begin{gathered}
q=\frac{a-c}{b(n+1)} \\
\pi=\frac{(a-c)^{2}}{b(n+1)^{2}}
\end{gathered}
$$

which are the standard outcomes for a Cournot Oligopoly and do not depend on the size of innovation $x$. Using eqs. (7) into (2), and knowing $r=x$, it is possible to write the upstream monopolist maximisation problem as:

$$
\max _{x} \frac{n(a-c)}{b(n+1)} x-\gamma x^{2}
$$

which leads to:

$$
x^{+}=\frac{n(a-c)}{2 b \gamma(n+1)}
$$

Using eq. (10) into (9), we can compute the innovator profits in equilibrium:

$$
\pi_{u}^{+}=\frac{n^{2}(a-c)^{2}}{4 b^{2} \gamma(n+1)^{2}}
$$

Consistently with the standard results in the literature, royalty-based revenues are increasing in the number of manufacturers, as fierce competition comes together

\footnotetext{
${ }^{7}$ Lapan and Moschini [2000] demonstrate that, in the particular case of more than one factor of production, if a new technology that increases the productivity of an input alters the price of at least another factor (by lowering its demand), then incomplete adoption of the superior technology may emerge also with a royalty based licensing scheme. However, here I focus on the standard case of a single input, or alternatively, of a technology that uniformly increases the productivity (cuts the costs) of all the factors of production.
} 
with larger industry output and, consequently, more royalties.

\subsection{Upfront fee licensing scheme}

Let us now turn to the case where the innovative technology is licensed via an uniform, non-discriminating upfront fee $F(x)>0$. The impossibility of price discriminating the manufacturers make the inventor to set a fee which elicit an inefficiently low level of utilisation of the new technology. However, in this case, the size of the innovation is a relevant information to determine the equilibrium number of licensees. As mentioned earlier, depending on the size of innovation and the competition intensity, a new technology can be defined as a non-drastic innovation or a k-drastic innovation. In the following sections, I focus on both the cases and I analyse the condition for a k-drastic innovation to be introduced.

\subsubsection{Non-drastic innovation}

First, let us consider the case of non-drastic innovation. In this case, the size of the innovation is small enough to allow non-adopting manufacturers to produce positive quantities of the final good by means of the standard technology - formally, $x \leq(a-c) / n$.

From the maximization of eq.(1), we can derive the manufacturers' output level, given the size of innovation.

$$
\begin{gathered}
q^{A}=\frac{a-c+(n-m+1) x}{b(n+1)} \\
q^{B}=\frac{a-c-m x}{b(n+1)}
\end{gathered}
$$

Where superscripts $A, B$ indicate whether the manufacturer adopts the innovative $(A)$ or the standard $(B)$ technology. Consequently, the manufacturers' profits be- 
come:

$$
\begin{gathered}
\pi^{A}=\frac{(a-c+(n-m+1) x)^{2}}{b(n+1)^{2}}-F \\
\pi^{B}=\frac{(a-c-m x)^{2}}{b(n+1)^{2}}
\end{gathered}
$$

Notice that, if $m=0$, then $\pi^{A}=\varnothing$ and $\pi^{B}=\frac{(a-c)^{2}}{b(n+1)^{2}}$. Instead, if $m=n$, then $\pi^{B}=\varnothing$ and $\pi^{A}=\frac{(a-(c-x))^{2}}{b(n+1)^{2}}-F$. It is possible to consider $\pi^{B}$ as the opportunity cost of adoption, as it represents the profits that the $m^{\text {th }}$ manufacturers would earn by producing the final good by means of the standard technology, all else equal.

These general payoffs can be used to derive the individual payoff of a firm which has to decide which technology to choose. From eqs. (12) and (13), we know that the output level depends on the number of firms that adopt the innovative technology. Therefore, each firm takes into consideration the adoption of the technology by her rivals in order to decide which choice is the profit maximizing one. The innovator is not allowed to price discriminate the manufacturers and can only set a uniform licensing fee $F$ that, given the size of the innovation and the intensity of competition, can elicit a certain number of adopters. Consider the case when the inventor wants to elicit the adoption of the new technology by exactly $m$ manufacturers: the problem of the $m^{\text {th }}$ firm, taking the size of the licensing fee $F$ as given, is to choose which strategy yields the best payoff: ${ }^{8}$

$$
\pi_{m}=\left\{\begin{array}{lll}
\frac{(a-c+(n-m+1) x)^{2}}{b(n+1)^{2}}-F & \text { if } & m \in A \\
\frac{(a-c-(m-1) x)^{2}}{b(n+1)^{2}} & \text { if } & m \in B
\end{array}\right.
$$

From eq.(16), we know that the $m^{\text {th }}$ firm chooses $A$ whenever:

$$
F \leq \frac{n x(2(a-c-x(m-1))+x n)}{b(n+1)^{2}}
$$

\footnotetext{
${ }^{8}$ As a tie-breaking rule, I assume the new technology is always preferred by the manufacturers if it comes at no extra costs.
} 
Eq.(17) represents the Participation Constraint of the inventor's maximization problem, which is marginally increasing in both the size of the innovation $x$ and the intensity of competition $n$, meaning that i) the inventor can charge a larger licensing fee for larger invention, and ii), interestingly, the same invention can be licensed at a higher price in a more competitive market. ${ }^{9}$

Now, the problem of the innovator can be written as:

$$
\begin{gathered}
\max _{m ; x} \pi_{u}=m F-\gamma x^{2} \\
\text { s.t. } F \leq \frac{n x(2(a-c-x(m-1))+x n)}{b(n+1)^{2}}
\end{gathered}
$$

By embedding the Participation Constraint into the innovator's profits, it is possible to rewrite eq.(18) as:

$$
\max _{x ; m} \pi_{u}=m \frac{n x(2(a-c-x(m-1))+x n)}{b(n+1)^{2}}-\gamma x^{2}
$$

From which we derive:

$$
\begin{gathered}
m^{\circ}=\frac{2 b \gamma(n+1)^{2}}{n(n+2)} \\
x^{\circ}=\frac{2 n(n+2)(a-c)}{8 b \gamma(n+1)^{2}-n(n+2)^{2}}
\end{gathered}
$$

For the innovation to be non-drastic $\left(x^{\circ}<(a-c) / m^{*}\right)$, the condition $\gamma>\frac{n(n+2)^{2}}{4 b(n+1)^{2}} \equiv \Gamma^{*}$ must hold. Moreover, this condition is sufficient to guarantee positive innovation size and output.

Eq.(20) represents the first results of this analysis. For sake of simplicity, let us define $\frac{n(n+2)}{(n+1)^{2}} \equiv N(n)$ as a monotonic transformation of the intensity of competition

\footnotetext{
${ }^{9}$ Eq. (17) represents a sufficient condition for the equilibrium to be stable. One can see that the Participation Constraint satisfies also $F>\frac{(a-c+(n-m) x)^{2}}{b(n+1)^{2}}-\frac{(a-c-m x)^{2}}{b(n+1)^{2}}-$ i.e., the condition under which the non-adopting firms do not prefer deviating by purchasing the innovation.
} 


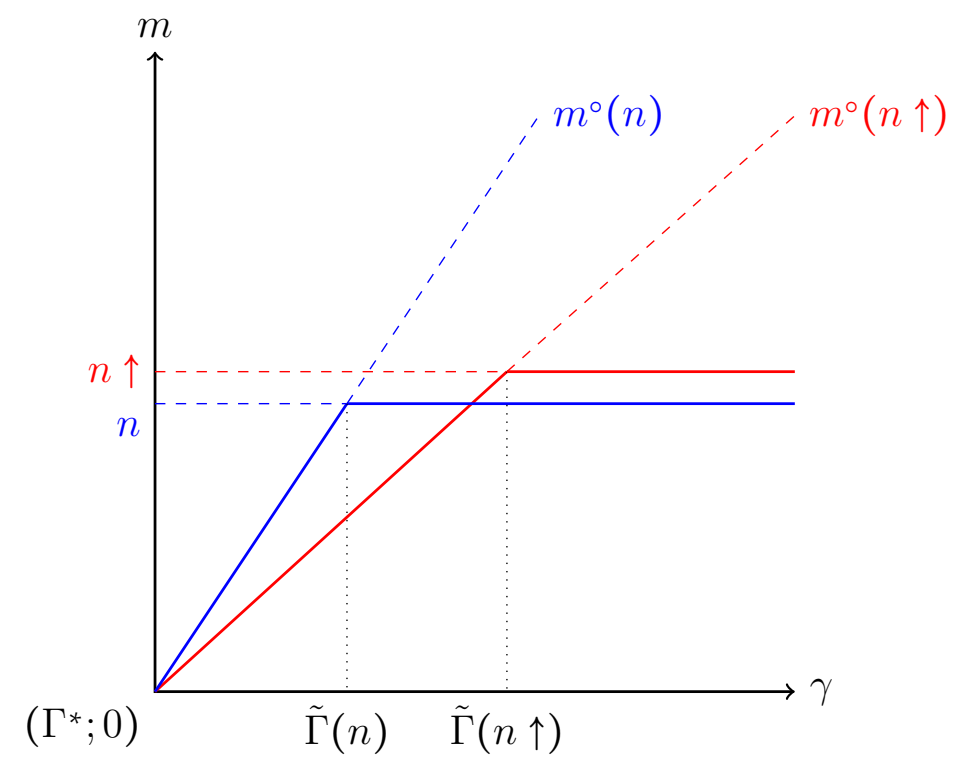

Figure 1: Optimal number of licensees $m$ and the cost of technology $\gamma$.

$\left(N_{n}^{\prime}>0\right)$. It is possible to rewrite eq.(20) as:

$$
m^{\circ}=\frac{2 b \gamma}{N(n)}
$$

Proposition 1. The number of manufacturers that adopt the innovative technology is decreasing in the intensity of competition and in the efficiency of the inventor, where:

$$
m= \begin{cases}m^{\circ} & \text { if } \gamma<\frac{n N(n)}{2 b} \equiv \tilde{\Gamma} \\ n & \text { otherwise }\end{cases}
$$

Corollary 1. The threshold in Proposition $1(\tilde{\Gamma})$ is increasing in n, meaning that when competition is more intense, relatively less efficient inventors are able to introduce larger innovations.

Figures 1 graphically represents Proposition 1 and Corollary 1. Instead, Figure 2 shows the condition in Proposition 1 in terms of the intensity of competition. ${ }^{10}$

\footnotetext{
${ }^{10}$ It is possible to rewrite the condition in Proposition 1 as: $m=m^{\circ}$ if $n>\tilde{n}(b \gamma)$
} 


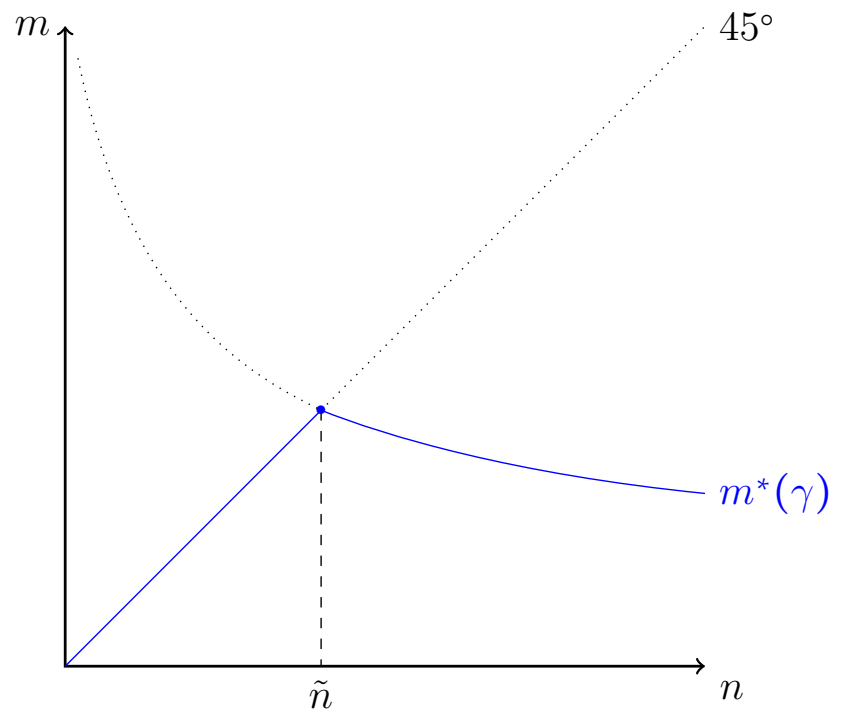

Figure 2: Equilibrium of licensees $m$ and the number of active firms $n$

Let us now compute the equilibrium outcomes of the game. Replacing eqs.(21) and (20) in the profit function of the inventor and the payoffs of the manufacturers, it is possible to derive:

$$
\begin{gathered}
\pi_{u}^{\circ}=\frac{4 n(a-c)^{2} \gamma}{8 b \gamma(n+1)^{2}-n(n+2)^{2}} \\
\pi^{A}=\frac{\left.(a-c)^{2}\left(4 b \gamma(n+1)^{2}-n^{2}(n+2)\right)^{2}\right)^{2}}{\left.b(n+1)^{2}\left(8 b \gamma(n+1)^{2}-n(n+2)^{2}\right)^{2}\right)^{2}} \equiv \hat{\phi} \pi_{0} \quad \text { with } \quad \hat{\phi}<1 \\
\pi^{B}=\frac{\left.(a-c)^{2}\left(4 b \gamma(n+1)^{2}-n(n+2)^{2}\right)^{2}\right)^{2}}{\left.b(n+1)^{2}\left(8 b \gamma(n+1)^{2}-n(n+2)^{2}\right)^{2}\right)^{2}} \equiv \hat{\theta} \pi_{0} \quad \text { with } \quad \hat{\theta}<1
\end{gathered}
$$

Where $\pi_{0}=(a-c)^{2} / b(n+1)^{2}$ is the n-oligopoly Cournot per-firm profits if the technology A was not available - i.e. when $\gamma \rightarrow \infty$. From a comparison of the payoffs of the manufacturers, it is possible to see that both the adopters and the non-adopters are worse off after the introduction of the new technology. This result is not surprising, as it is a standard conclusion for fixed fee licensing contracts and I implicitly assume that the innovator has the full right to set the licensing fee he prefers. Interestingly though, when competition is more intense $(n \uparrow)$, the profits of the downstream producers shrink, while the profits of the inventor increase. While the former process may be partially explained by the increase in the competitive 
pressure, the latter is due to the fall of the opportunity cost of adoption of the manufacturers and the raise in the extractive capacity of the inventor. We can refer to it as the "hidden bargaining power" of the upstream patentee.

Finally, the total output is:

$$
Q=m^{\circ} q^{A}+\left(n-m^{\circ}\right) q^{B}=q_{0} \lambda
$$

where

$$
\lambda=\frac{4 b \gamma(n+1)^{2}(2 n+1)-n^{2}(n+2)^{2}}{8 b \gamma(n+1)^{2}-n(n+2)^{2}}>n
$$

From eq.(26), we can write:

Remark 1. Innovation has always a positive effect on the Consumer surplus, as it increases the output and lowers the market price of the final good, by improving the efficiency of the production process.

Intuitively, from a welfare perspective, we observe underinvestment in $R \& D$, as the innovator does not take into consideration the Consumer surplus in its maximisation problem, while a policy maker does. However, even considering a policy-maker who is totally private-oriented - i.e., a policy-maker who assigns a zero-weight to Consumer Surplus - one can see that the presence of an old technology that raises the opportunity cost of adoption poses the problem of double marginalization. Therefore, even in the extreme case of a private-oriented policy-maker, we would observe underinvestment in equilibrium. To avoid this problem and establish efficient investments, the policy-maker should mandate a switch off of the old technology and let the innovator supply the new one in complete monopoly. However, a switch off of the old technology means that the supplier of the new technology would be able to extract the entire Producer surplus and that, crucially, only the adopters would be able to produce the final good. Therefore, as monopoly guarantees the highest Producer surplus, the innovator would set a sufficiently high licensing fee (equal to monopoly profits) to elicit the adoption by one firm only. Although this may be op- 
timal from a pure Producer surplus perspective, it may worse off Consumer surplus by raising the market price in equilibrium. To give an example, consider the case of a market with $n$ manufacturers, where market price is $P=\frac{n c+a}{n+1}$. A switch off of the old technology would drive the market towards an "efficient" monopoly - i.e., a monopoly where production occurs by means of the new technology. This would alter the price of the final good to $P^{M}=\frac{c+a-x}{2}$. Consumer surplus increases if and only if:

$$
P^{M}=\frac{c+a-x}{2}<\frac{n c+a}{n+1}=P \quad \Leftrightarrow \quad x>\frac{n-1}{n+1}(a-c)
$$

After computing all the algebra, we have:

$$
P^{M}<P \quad \text { if } \quad \gamma<\frac{n}{2 b(n-1)}
$$

Which means that only a very efficient innovator can achieve a similar result. It is possible to summarise these results as:

Proposition 2. The monopolist inventor underinvests in R\&D. Removal of the standard technology (B) would induce an equilibrium investment in innovation that maximises the Producer surplus. However, if the inventor is not sufficiently efficient, such a policy makes consumers worse off.

\subsubsection{Industry shake-outs: k-drastic innovations}

So far, I have only considered the case of a small innovation that does not alter the number of active firms in the market. Even under incomplete adoption, all the manufacturers produce positive quantities, and thus no potential sources of concern emerge from a Social Welfare perspective. Moreover, a larger rate of adoption is always beneficial to the Consumer surplus, as it necessarily comes together with a larger industry output and, consequently, a lower price of the final good.

In this section, I drop this assumption and extend the analysis to large innovations. Following Sen and Tauman[2007], let us define a k-drastic innovation as a 
cost-reducing technology which is large enough to imply the exit of non-adopting manufacturers when the innovation is sold to at least $k \geq 1$ manufacturers. From Arrow [1962], we know that a drastic innovation consists in a large cost reduction that allows the innovator to set a monopoly price below the rival's marginal costs. This kind of innovation can be considered as a 1-drastic innovation, where the adoption by only one firm is sufficient to prevent any non-adopting firm from producing positive quantities of the final good. Formally, a k-drastic innovation implies $k=\frac{a-c}{x}$. When $m<k$ manufacturers pay the licensing fee, output expansion is relatively small and non-adopters are still able to produce positive quantities of the final good and stay in the market. Instead, when $m \geq k$, the adopters' output expands to such an extent that the price of the final good falls at the marginal costs of production faced by non-adopters, who are not allowed to produce any positive quantities.

It can be proved that the optimal number of licensees never exceeds $m^{*}=k=\frac{a-c}{x}$ (see Kamien and Tauman [1986]). The reason for this result is straightforward. If the number of licensees is $m^{*}=k$, by eqs.(12) and (13), we know that the final good is entirely produced by adopters by means of the new technology. Therefore, Producer surplus is simply the k-oligopoly industry profits - i.e., the sum of the profits made by the $m=k$ adopters. In order to extract part of the Producer surplus, the innovator sets a licensing fee that is equal to the difference between the gains deriving from the adoption of the innovation $\left(\pi^{A}\right)$ and the opportunity cost of adoption $\left(\pi^{B}\right)$. In other words, as in the previous section, the $m^{\text {th }}$ firm is made indifferent between adopting the new technology and produce with the standard one.

Suppose now that the innovator decides to license an additional manufacturer to produce with the patented technology. Now, the number of active manufacturers becomes $m^{\prime}=k+1$ and the Producer surplus is the $(\mathrm{k}+1)$-oligopoly industry profits. The opportunity cost of adoption is zero in this case, as it is not possible for any firm to produce positive quantities with the standard technology. Thus, the licensing fee set by the supplier is equal to $\pi^{A}$. This is true for any $m>k$, but, as Producer surplus 
is decreasing in the number of active firms, any additional firm endowed with the innovative technology implies lower profits for the innovator. Thus, the equilibrium number of licensees is never above $m^{*}=k$. Instead, if $m^{*}<k$, non-adopters are able to produce positive quantities of the final good. This implies a re-allocation of the Producer surplus to non-adopters and a lower ability of the innovator to extract the surplus of the invention he sells.

In this section, I focus on innovations that satisfy $k \geq \frac{a-c}{x}$, where $k<n$. In fact, as I am not assuming free entry, when $k \geq n$, the innovation can be considered as a non-drastic one and we go back to the non-drastic innovation scenario, which is analysed in Section 3.

Remark 2. In case of $k$-drastic innovation, where $k=\frac{a-c}{x}<n$, the optimal number of licensees is $m^{*}=k$.

Apparently, Remark 2 implies that the number of licensees is independent from the number of firms in the market and depends on the pre-innovation cost $c$ and the size of the innovation $x$. I show that, as competition affects the size of the innovation, it also has an impact on the equilibrium number of licensees $(m)$. Let us consider the value $m(x)=\frac{a-c}{x}=k$. When the innovator sells the innovation to $m(x)$ manufacturers, non-adopters exit the market and the equilibrium output of adopters is:

$$
q^{A}(x)=\frac{(a-c+x)}{b\left(\frac{a-c}{x}+1\right)}=\frac{x}{b}
$$

The total industry output is $Q=m(x) q^{A}(x)=\frac{a-c}{b}$ and the market price is $P(Q)=$ $a-b(Q)=c$. Similarly to the previous section, the licensing fee paid by the adopters cannot exceed the difference between the profits they earn with the new technology, minus their opportunity cost of adoption (Participation Constraint):

$$
F(x) \leq \frac{x^{2}}{b}-\frac{a-c-\left(\frac{a-c}{x}-1\right) x}{b(n+1)^{2}}=\frac{n(n+2) x^{2}}{b(n+1)^{2}}
$$


Which also implies that, in equilibrium, adopters earn:

$$
\pi^{A}(x)=\frac{x^{2}}{b(n+1)^{2}}
$$

Instead, the profits of the innovator consist of the sum of all the fixed fees collected minus the investment in the cost-reducing innovation $I(x)=\gamma x^{2}$ :

$$
\pi_{u}(x)=m^{*} F-I(x)=\frac{n(n+2)}{b(n+1)^{2}} x(a-c)-\gamma x^{2}
$$

By embedding the Participation Constraint in the maximization problem of the inventor, simple maximization w.r.t. $x$ yields the optimal size of the innovation:

$$
x^{*}=\frac{n(n+2)(a-c)}{2 b \gamma(n+1)^{2}}
$$

from which we derive:

$$
\pi_{u}^{*}=\frac{n^{2}(n+2)^{2}(a-c)^{2}}{4 b^{2} \gamma(n+1)^{4}}
$$

I use $x^{*}$ to compute the optimal number of licensees:

$$
m^{*}=\frac{2 b \gamma(n+1)^{2}}{n(n+2)}
$$

which is a decreasing function of $n$ and coincides with the number of licenses derived in the case of non-drastic innovations. Remember from Section 3 that $N(n)=\frac{n(n+2)}{(n+1)^{2}}$; we can rewrite $m^{*}=\frac{2 b \gamma}{N(n)}$.

From eq.(30), we are able to state the following proposition:

Proposition 3. The equilibrium number of licensees with $k$-drastic innovation is $m=2 b \gamma / N(n)$. Moreover, the number of licensees decreases when competition increases.

Proposition 3 extends the results in Kamien and Tauman[1984, 1986], by considering the size of the innovation as a variable which is not exogenously given, 
but depends on the environment in which the innovator is operating. Moreover, Proposition 3 shows that, as the innovator's investments depend on competition, the equilibrium number of licensees is also connected to the initial number of manufacturers operating in the market. As competition becomes stronger, the incentives to invest in innovation increase too, because the competitive pressure lowers the opportunity cost of adoption of the manufacturers. When the incentives to invest grow, the innovator's effort increases and so does the size of the innovation. Therefore, we expect that, in concentrated markets, where the incentives to invest are relatively weak, innovators are more likely to introduce small innovations. As competition becomes stronger, the incentives to invest grow positively affecting the size of the innovation, which becomes more drastic.

The implications of k-drastic innovations are several. Proposition 3 states that the upper bound of $m^{*}$ is lower in markets with several manufacturers. That is, the more competitive the market, the more drastic the innovation, and consequently the fewer the active post-innovation manufacturers. This means that competition also affects the magnitude of the shake-outs after the introduction of an innovation. As the feasible size of $m^{*}$ decreases because of competition, the shake-out is expected to be more severe.

Also, it is worth spending few words on the cost parameter $\gamma$. Similarly to the previous section with small innovations, $\gamma$ represents the cost associated to the $R \& D$ activities and can be interpreted as a proxy for the innovator's efficiency. The higher $\gamma$, the more the innovator must pay to obtain a given size of innovation - i.e., the efficiency parameter $\gamma$ affects the size of the innovation produced, as it alters the innovator's cost of investing in innovation. Therefore, an efficient innovator is more likely to produce a more drastic innovation than an inefficient one. Formally,

$$
x_{\gamma}^{\prime}=-\frac{N(n)}{2 b \gamma^{2}}(a-c)<0
$$


Also, we already know that a k-drastic innovation implies $k x \geq(a-c)$. Using eq. (28), we can write:

$$
k \geq \frac{2 b \gamma}{N(n)}
$$

which can be re-written in terms of the cost parameter $\gamma$ :

$$
\gamma \leq \frac{k N(n)}{2 b} \equiv \hat{\Gamma}(k, n)
$$

Eq. (31) represents the efficiency requirement the innovator must satisfy in order to be able to produce a k-drastic innovation. The less drastic the innovation $(k \uparrow)$, the less strict this condition $(\hat{\Gamma}(k, n) \uparrow)$. Intuitively, less drastic innovations are achievable by less efficient innovators. However, competition alters the efficiency requirement acting as a subsidy for innovators $\left(\hat{\Gamma}_{n}^{\prime}>0\right)$. The logic behind this result is simple and consistent with the previous part of the article, as it follows from the fact that competition acts as a trigger for the incentives and the size of the innovation $\left(x_{n}^{\prime}>0\right)$. Since the opportunity cost of adoption decreases more than the gains when competition becomes stronger, the innovator can charge a larger licensing fee for the same number of licensees. Therefore, in equilibrium, innovation increases in size and becomes more drastic. We can summarise this analysis and state that:

Corollary 2. The more efficient the innovator $(\gamma \downarrow)$, the more drastic the innovation. However, competition subsidises less efficient innovators in producing $k$-drastic innovations.

Finally, let us compare the results above with those derived in Section 3: for the innovation to be k-drastic, we must have:

$$
m^{*}=\frac{2 b \gamma(n+1)^{2}}{n(n+2)}<n \Longleftrightarrow \gamma<\frac{n^{2}(n+2)}{2 b(n+1)^{2}} \equiv \tilde{\Gamma}
$$

It is easy to show that, for any $n \geq 2$, it is true that $\tilde{\Gamma} \geq \Gamma^{*}=\frac{n(n+2)^{2}}{4 b(n+1)^{2}}$ - which 


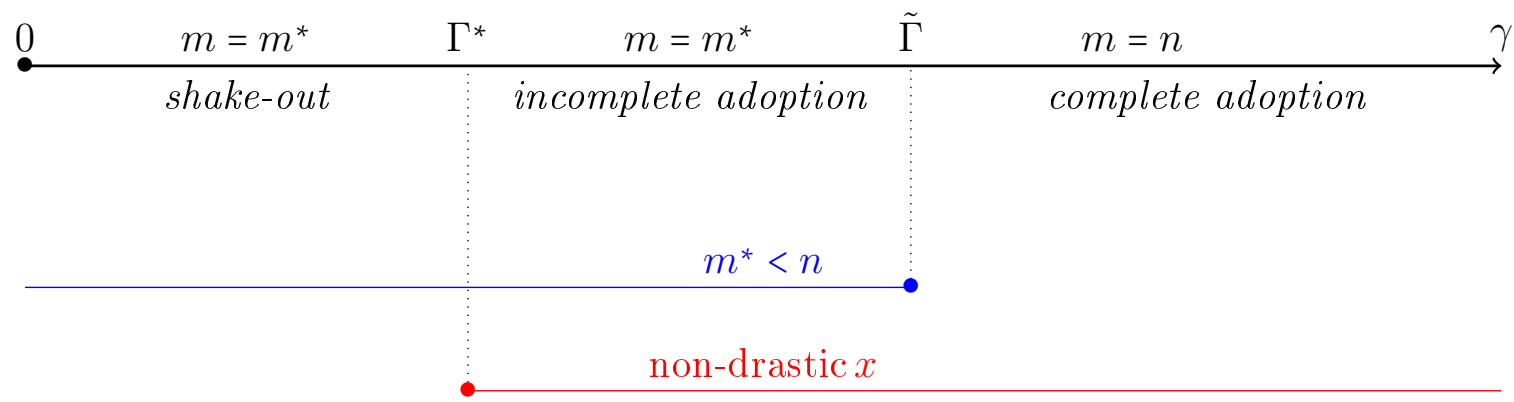

Figure 3: The effects of innovation on market structure, depending on the efficiency of the innovator $\gamma$.

is the lower bound of $\gamma$ for non-drastic innovations derived in Section 3. Then, $\Gamma^{*}$ is the efficiency threshold that sorts inventors who are sufficiently efficient to introduce a drastic innovation from those who are not, while $\tilde{\Gamma}$ sorts inventors that elicit incomplete adoption of the superior technology from those who elicit complete adoption. Interestingly, and consistently with both Corollary 1 and Corollary 2, both the thresholds are negatively related to the intensity of competition $\left(\Gamma_{n}^{*}, \tilde{\Gamma}_{n}>0\right)$. It follows that:

Proposition 4. Consider an inventor $\ell$. We observe the following cases:

i) if $\gamma_{\ell}<\Gamma^{*}$, we have a $k$-drastic innovation and the non-adopters' exit from the market;

ii) if $\Gamma^{*}<\gamma_{\ell}<\tilde{\Gamma}$, we have a non-drastic innovation and incomplete adoption;

iii) if $\gamma_{\ell}>\tilde{\Gamma}$, we have a non-drastic innovation and complete adoption.

Corollary 3. The more intense the competition in the product market, the higher the threshold $\Gamma^{*}$ and the easier it is to introduce a $k$-drastic innovation. However, competition softens the effects of the new technology on the price of the final good, while it increases the firms' markups.

Figures 3 and 4 show Proposition 4 and Corollary 3, respectively.

Let us focus on Figure 3. In both panels, the horizontal axis measures the inverse of innovation costs - i.e. the efficiency of the inventor. As $1 / \gamma$ increases, 


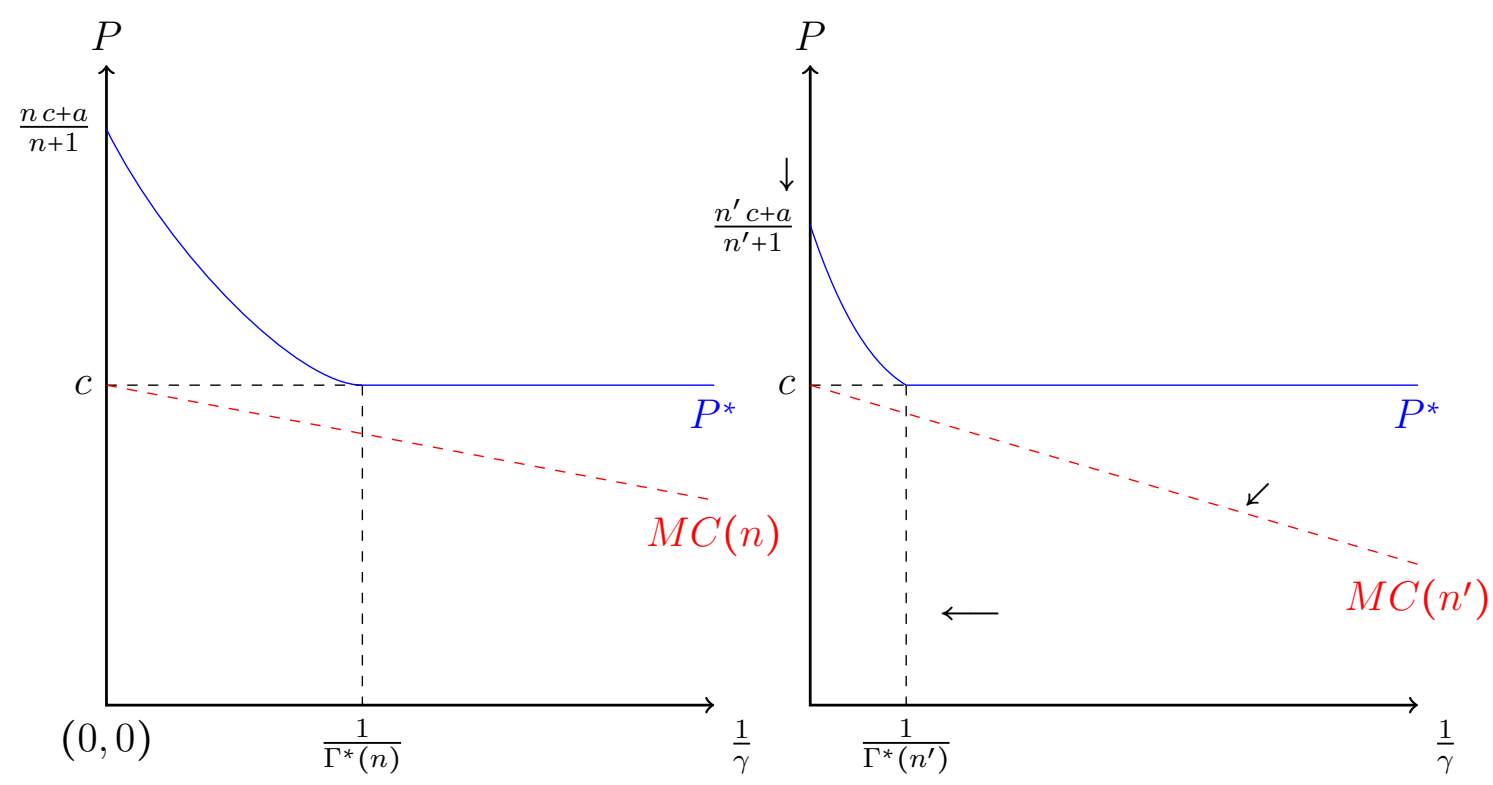

Figure 4: The effect of innovation on the market price $P$ and the marginal costs of downstream producers $M C$ with different market structures $n^{\prime}>n$. The size of the innovation is measured in terms of innovator's efficiency $1 / \gamma$ (given the market structure). The more competitive the market (right hand panel), the less effective the innovation in lowering the price of the final good. When the market is highly competitive, inefficient inventors (high $\gamma$ ) are relatively more effective in introducing larger innovations.

everything else being equal, the innovation introduced is bigger. The two panels are associated to two different market structures, with $n$ and $n^{\prime}>n$ downstream producers, respectively. As competition becomes more intense, it is easier to produce a k-drastic innovation also for relatively inefficient inventors - i.e., $1 / \Gamma^{*}$ shifts to the left. Moreover, the effect of innovation on the market price $P^{*}$ is lower - i.e. $\frac{n c+a}{n+1}>\frac{n^{\prime} c+a}{n^{\prime}+1}$. Instead, the downstream producers' marginal costs $(M C=c-x)$ fall more sharply, as competition prompts the size of the innovation $\left(x_{n}^{\prime}>0\right)$. This means that when the market is highly competitive, it is more likely that the introduction of a new technology raises markups (marginal costs fall more than the market price). However, this is mainly driven by the change in the cost structure of the firms that have now to repay a fixed cost component - i.e. the licensing fee - and it is not associated to a fall in the Consumer surplus. 


\subsection{Discussions and Welfare implications}

From the Social Welfare perspective, k-drastic innovations imply a clear and general increase in Social Welfare, defined as the sum of Consumer and Producer surplus. In fact, by lowering the market price to the pre-innovation marginal costs of production and increasing the efficiency of the production process, k-drastic innovations have a positive impact on both the components of Social Welfare.

If we look at the optimal size of the innovation, we observe underinvestment in $R \& D$ in equilibrium, as the upstream innovator does not internalise the Consumer surplus in his maximization problem, and the presence of an alternative technology prevents the innovator from fully extracting Producer surplus. If we consider the problem of a policy-maker that wants to maximize Social Welfare, we have:

$$
S W=\frac{b Q^{2}}{2}+(a-c+x-b Q) Q-\gamma x^{2}
$$

Simple maximization w.r.t. total output and the size of the innovation leads to, respectively:

$$
\begin{gathered}
Q^{w}=\left(\frac{2 b \gamma}{2 b \gamma-1}\right) \frac{a-c}{b}>Q^{*} \\
x^{w}=\frac{a-c}{2 b \gamma-1}>x^{*}
\end{gathered}
$$

The policy-maker expects a larger output and more investments in R\&D. However, it is impossible to reach an efficient allocation in a market where a k-drastic patented innovation is introduced. In fact, the monopolist innovator is always able to keep the market price at the pre-innovation competitive level by lowering the number of active firms and controlling the total output produced. We can refer to this ability of the inventor as the "hidden bargaining power". The analysis of the potential effects (either positive or negative) of such a distribution of the surplus generated by the introduction of the new technology is beyond the scope of this article. Here, I simply show that a process of market power accumulation by the inventor is a 
possible outcome and the policy-makers' concerns may be valid.

The innovator benefits from operating in a competitive market $\left(\partial \pi_{u}^{*} / \partial n>0\right)$, as he can appropriate all the surplus generated by innovation. The more competitive the market, the higher the licensing fee paid for adoption and the lower the adopters' profits in equilibrium $\left(\partial \pi_{d}^{A} / \partial n<0\right)$. Thus, inventions in perfectly competitive markets generate a surplus which entirely increases Producer surplus (the price does not change) and is fully appropriated by the innovator. Instead, when the market is highly concentrated, part of the surplus generated by innovation goes to Consumer surplus by lowering the price of the final good from $n(c+a) /(n+1)$ to $c$. Moreover, the innovator's surplus extraction is frustrated also by the fact that manufacturers with large market power have a high opportunity cost of adoption and are more reluctant to pay a large licensing fee. It is possible to summarise these results as:

Proposition 5. The effect of a $k$-drastic innovation on the Consumer surplus is always positive. Moreover, it the magnitude of the effect does not vary regardless of the size of the industry shake-out. However, the more firms are driven out of the market, the larger the markups of the adopting manufacturers, and the larger the profits of the inventor.

Finally, looking at the incentives to invest in innovation, it is apparent that competition in the downstream sector is beneficial to the innovator's effort of producing a large innovation. This is in line with the Arrowian theory, according to which the manufacturers are willing to pay a larger fee to leapfrog the rivals when competition is stronger. However, things are less clear when we look at the innovator's sector. Here, the analysis focuses on the case of a monopolist inventor who benefits from patent protection that prevents competition in the innovative technologies. Dropping this assumption makes the analysis fuzzy. On the one hand, competition reduces the ability of the innovator to appropriate the value generated by his invention, generating the well-known hold-up problem, which may further lower the already insufficient investments in $\mathrm{R} \& \mathrm{D}$. On the other hand, many firms compet- 
ing in the R\&D stages may prompt replication of efforts, inducing overinvestments. Competition in R\&D, however, decreases the licensing fee, increases the manufacturers' surplus, and reduces the market price to a lower level than a patented k-drastic innovation. Thus, the effect of competition among inventors, although ambiguous, highlights the fact that both competition and concentration might be required to stimulate investments in $\mathrm{R} \& \mathrm{D}$ and there might not be a superior market structure.

\section{The choice of the licensing scheme: a comparison of the incentives}

Finally, in this section, I solve the first stage of the game $(t=0)$, where the innovator chooses which licensing contract to enforce in order to sell his innovation to the manufacturers. From 3.1, we know that the innovator profits if he licenses the invention via royalties would be eq. (11), regardless of the magnitude of the innovation $x$. In fact, for the innovator is always profitable to sell the technology to an additional manufacturers.

Instead, if the licensing scheme enforced by the inventor is an upfront fee, then the magnitude of innovation does matter in order to determine the revenues from licensing. In particular, in section 3.2.1, we have seen the case of non-drastic innovations, where the inventor's profits are defined by eq. (23). This scenario applies if the condition $\gamma \geq \Gamma^{*}$ holds. Otherwise, when $\gamma<\Gamma^{*}$, the innovator is able to develop a k-drastic innovation and to earn profits as defined by eq. (29) in Section 3.2.2.

Therefore, in order to determine the optimal licensing scheme from the inventor's perspective, we have to compare all the outcomes, case by case.

$$
\pi_{u}(F)>\pi_{u}(r) \Leftrightarrow \begin{cases}\frac{n^{2}(a-c)^{2}}{4 \gamma b^{2}(n+1)^{2}}<\frac{n^{2}(n+2)^{2}(a-c)^{2}}{4 b^{2} \gamma(n+1)^{4}} & \text { if } \gamma<\Gamma^{*} \\ \frac{n^{2}(a-c)^{2}}{4 \gamma b^{2}(n+1)^{2}}<\frac{4 n(a-c)^{2} \gamma}{8 b \gamma(n+1)^{2}-n(n+2)^{2}} & \text { otherwise }\end{cases}
$$




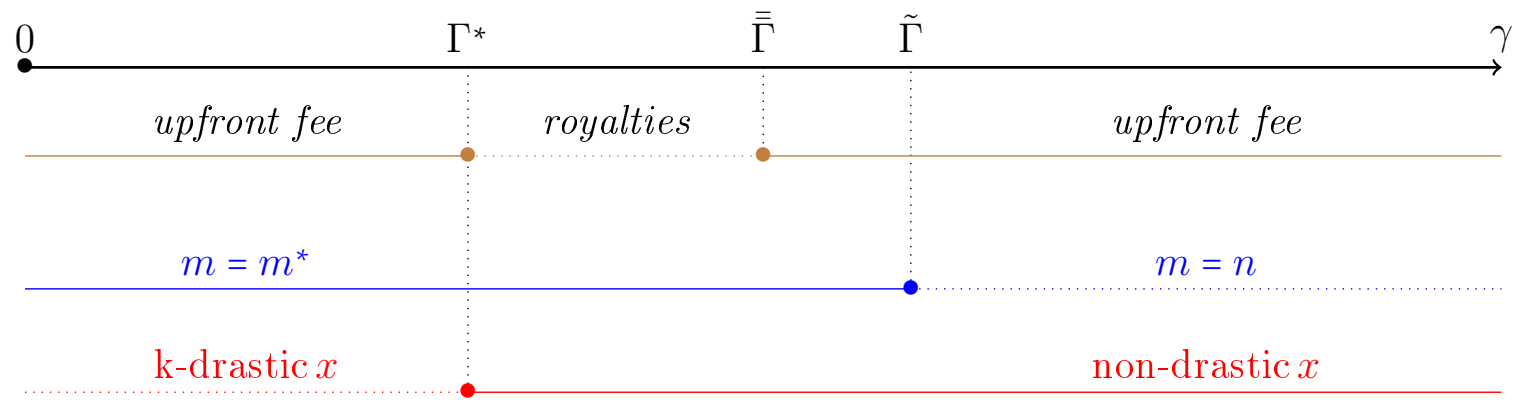

Figure 5: the innovator chooses the licensing contract depending on his own efficiency (and competition level). When the innovation is k-drastic, upfront fee is always preferred to royalties. The same when the innovator is very inefficient. Insteade, for intermediate value of $\gamma$, royalties are superior to upfront fee.

Since $n^{2}(n+2)^{2} /(n+1)^{4}>n^{2} /(n+1)^{2}$, the first condition in eq.(32) is always satisfied. Instead, the second condition is satisfied for $\gamma>\overline{\bar{\Gamma}}>\Gamma^{*}$, as:

$$
\begin{gathered}
\frac{4 n(a-c)^{2} \gamma}{8 b \gamma(n+1)^{2}-n(n+2)^{2}}-\frac{n^{2}(a-c)^{2}}{4 \gamma b^{2}(n+1)^{2}}>0 \\
\frac{\left(4 \gamma b^{2}(n+1)^{2}\right)\left(4 n(a-c)^{2} \gamma\right)-\left(8 b \gamma(n+1)^{2}-n(n+2)^{2}\right)\left(n^{2}(a-c)^{2}\right)}{\left(8 b \gamma(n+1)^{2}-n(n+2)^{2}\right)\left(4 \gamma b^{2}(n+1)^{2}\right)}>0 \\
\frac{(a-c)^{2} n\left(\left(8 b \gamma(n+1)^{2}\right)(2 b \gamma-n)+n^{2}(n+2)^{2}\right)}{\left(8 b \gamma(n+1)^{2}-n(n+2)^{2}\right)\left(4 \gamma b^{2}(n+1)^{2}\right)}>0
\end{gathered}
$$

The denominator is always positive for $\gamma>\Gamma^{*}$. The numerator is positive if $\gamma>\frac{n\left((n+1)+\sqrt{n^{2}+3 n+3}\right)}{4 b(n+1)} \equiv \overline{\bar{\Gamma}}$. Furthermore, one can see that $\Gamma^{*}<\overline{\bar{\Gamma}}<\tilde{\Gamma}$.

Proposition 6. The upfront fee licensing scheme provides always higher incentives to the innovator than a royalty based contract if the innovation is $k$-drastic-i.e., if the innovator is sufficiently efficient $\left(\gamma<\Gamma^{*}\right)$. When the innovation is non-drastic, if the innovator is sufficiently efficient $(\gamma<\overline{\bar{\Gamma}})$, then royalty-based contract is preferred to upfront fee. Otherwise, when the innovator is not very efficient $(\gamma>\overline{\bar{\Gamma}})$ - and therefore when the innovation is small - then upfront fee is preferred to royalties.

This result is at odds with the findings in Sen and Tauman [2019] and Sen[2005], where the authors find royalty based licensing contracts may are superior to upfront fees if the number of competitors in the product market is sufficiently high. The 
reason of this divergence is to be found in the positive effect that an increase in product market competition has on the surplus extraction of the innovator. In Sen [2005], in fact, the size of innovation is taken as given and is not influenced by the market variables. Here, instead, the size of the cost reducing effect is a choice variable of the innovator, who decides how many resources to invest anticipating the manufacturers adoption decision and observing the market characteristics. If the innovator licenses the new technology by means of an upfront fee, competition in the product market both reduces the equilibrium number of adopters and increases the equilibrium size of the innovation, thus enlarging the extraction ability of the monopolist innovator. Thus, licensing revenues under upfront fee are not bounded to a maximum level, contrary to the case with exogenous size.

\section{Conclusion}

I show that competition in the pre-innovation downstream sector is relevant to determine the rate of adoption of a superior technology when it is licensed by a licensing fee. Moreover, competition in the downstream sector influences the decision of an upstream innovator about the size of the innovation, which is an important element to determine the equilibrium number of licensees. The analysis is divided into two parts: first, I analyse the rate of adoption when the innovation is small and all the firms, both adopters and non-adopters, produce positive quantities of the final good. Then, I investigate the diffusion of a k-drastic innovation - i.e., a sufficiently large innovation that, when adopted by at least $k$ manufacturers, forces non-adopting rivals to exit the market. In both cases, I show that competition negatively affects the equilibrium number of adopters of the new technology. Finally, I compare the results in the two scenarios and identify some thresholds that help understand the possible impact of the introduction of a new technology, given the intensity of competition and the efficiency of the inventor. 
Interestingly, the effect of a cost-reducing innovation on the Consumer surplus is weaker when competition is stronger. Moreover, if the market is perfectly competitive, introducing an innovation does not alter the market price and the total output, regardless of the size of the cost-reducing effect. This result suggests that monopolist innovators able to produce large innovations are entitled to be market makers. Thus, the post-innovation markets become impervious to competition and external regulation. The problem of market power accumulation by the so-called superstar firms is a topical issue and this paper suggests that such a process is compatible with the introduction of a new technology in a vertical market. However, an analysis of the impact of this market power accumulation on the economy is beyond the scope of this article and is left aside as a subject for future investigations.

\section{References}

[1] Aghion, P., Bloom, N., Blundell, R., Griffith, R., and Howitt, P. (2005) Competition and innovation: an inverted-U relationship, The Quarterly Journal of Economics, Vol 120 (2), pp. 701-728.

[2] Alipranti, M., Milliou, C., and Petrakis E. (2015), On vertical relations and the timing of technology adoption, Journal of Economic Behavior $\&$ Organization, 120, pp. 117-129.

[3] Arora, A. and Fosfuri, A. (2019), Licensing the market for technology, Journal of Economic Behavior 83 Organization, 52(2), pp. 277-295.

[4] Arrow, K. (1962), 'Economic welfare and the allocation of resources for invention,' in R. R. Nelson (ed.), The Rate and Direction of Inventive Activity. Princeton University Press: Princeton, NJ, pp. 609-625.

[5] Bakaouka, E. and Milliou, C. (2018), Vertical licensing, input pricing and entry, International Journal of Industrial Organization, 59, pp. 66-96. 
[6] Beneito, P., Coscollà-Girona, P., Rochina-Barrachina, M. E., and Sanchis, A. (2015), Competitive pressure and innovation at the firm level, The Journal of Industrial Economics , 63(3), https://doi.org/10.1111/joie.12079.

[7] Berry, A., Gaynor, M., and Morton, F.S. (2019), Do increasing markups matter? Lessons from empirical industrial organization, Journal of Economic Perspectives, 33 (3), pp. 44-68.

[8] Gallini, N. T. and Wright, B. D. (1990), Technology transfer under asymmetric information, RAND Journal of Economics, 21(1), pp. 147-160.

[9] Geroski, P. A. (1995), What do we know about entry, International Journal of Industrial Organization, 13(4), pp. 421-440.

[10] Hermosilla, M. and Wu, Y. (2018), Market size and innovation: the intermediary role of technology licensing, Research Policy, 47(5), pp. 980-991.

[11] International Monetary Fund [2019], World Economic Outlook: Growth slowdown, precarious recovery, Washington, DC, April.

[12] Jovanovic, B. and McDonald, G. (1994), The life cycle of a competitive industry, Journal of Political Economy, 102(2), pp. 322-347.

[13] Katz, M. L. and Shapiro, C. (1985), On the licensing of innovations, RAND Journal of Economics, 16(4), pp. 504-520.

[14] Katz, M. L., Ordover J. A., Fisher, F. and Schmalensee, R. (1990), R\&D cooperation and competition, Brooking Papers on Economic Activity. Microeconomics, pp. $137-203$.

[15] Kamien, M. I., Oren, S. S. and Tauman, Y. (1992), Optimal licensing of cost reducing innovation, Journal of Mathematical Economics, 21, pp. 483-508.

[16] Kamien, M. I. and Tauman, Y. (1986), Fees versus royalties and the private value of a patent, Quarterly Journal of Economics, 101(3), pp. 471-492. 
[17] Klepper, S. (1996), Entry, exit, growth and innovation over the product life cycle The American Economic Review, 86(3), pp. 562-583.

[18] Klepper, S. and Simons, K. L. (2005), Industry shakeouts and technological change, International Journal of Industrial Organization, 42 (2), pp. 665-693.

[19] Lamoreaux, N.R. (2019), The problem of bigness: from Standard Oil to Google, Journal of Economic Perspective, 33 (3), pp.94-117.

[20] Lapan, H. R. and Moschini, G. (2000), Incomplete adoption of a superior technology, Economica, 67, pp.525-542.

[21] Marshall G. and Parra, A. (2019), Innovation and competition: the role of the product market, International Journal of Industrial Organization, 65, pp. 221-247

[22] Milliou, C. and Petrakis, E. (2011), Timing of technology adoption and product market competition, International Journal of Industrial Organization, 29 (5), pp. 513-523.

[23] Parra, A. (2019), Sequential innovation, patent policy and the dynamics of the replacement effect, RAND Journal of Economics, 50(3), pp. 568-590.

[24] Sen, D. and Tauman, Y. (2007) General licensing scheme for a cost reducing innovation, Games and Economic Behaviour, 59, pp. 163-186.

[25] Vives, X. (2008), Innovation and competitive pressure, Journal of Industrial Economics, 56 (3), pp. 419-469.

[26] Voudon, B. (2019), Vertical integration and technology adoption. Available at http://dx.doi.org/10.2139/ssrn.3358302. 


\section{Appendix A.1}

\section{Product differentiation}

Throughout Sections 2-3, I assume firms sell homogeneous products. As already mentioned, such a simplification does not hide any fundamental result and it is therefore made in order to keep the analysis as simple as possible. However, here I am going to change this assumption with a more general one. Consider the same setting as illustrated in Section 2, but instead of identical firms that produce the same good, let us assume that the downstream sector is populated by $n$ firms that produce differentiated products, with $\beta$ being the parameter that indicates how the products differ. If $\beta=1$, the final goods produced are identical and we go back to the case analysed in the core part of the article; instead, if $0<\beta<1$, the firms produce final goods which are not perfect substitute. For technical reason, I do not consider independent goods - i.e., $\beta=0$, which would imply monopoly. Instead, I assume $\beta>2 / n \equiv \beta$. In this way, it is possible to test the robustness of the main results derived above with a different measure of competition - i.e., the degree of product differentiation. The inverse demand function faced by each manufacturer becomes:

$$
P_{i}(Q)=a-b\left(q_{i}+\beta \sum_{j \neq i} q_{j}\right)
$$

with $i, j=1, \ldots, n$. For sake of simplicity, in what follows, I set the slope of the inverse demand function $b=1$.

Let us rewrite eq. (1) accordingly:

$$
\pi_{i}= \begin{cases}\left(a-q_{i}-\beta Q_{j \neq i}-(c-x)\right) q_{i}-F(x) & \text { if } \quad i \in A \\ \left(a-q_{i}-\beta Q_{j \neq i}-c\right) q_{i} & \text { if } \quad i \in B\end{cases}
$$

while eq. (2) does not vary.

The structure of the game is the same as shown in Section 2; first, from eq. (33) 
I derive the solution of the downstream subgame, given the size of innovation $x$ and the licensing fee $F(x)$; then, I go backward to the innovator's problem and I find the equilibrium size of $x$ and number of adopters $m$.

Let us rewrite eqs. (12), (13), (14), and (15) according to the new setting:

$$
\begin{gathered}
q^{A}=\frac{(a-c)(2-\beta)+(2+\beta(n-m-1))}{(2-\beta)(2+\beta(n-1))} \\
q^{B}=\frac{(a-c)(2-\beta)-m \beta x}{(2-\beta)(2+\beta(n-1))} \\
\pi^{A}=\frac{((a-c)(2-\beta)+(2+\beta(n-m-1)))^{2}}{((2-\beta)(2+\beta(n-1)))^{2}}-F(x) \\
\pi^{B}=\frac{((a-c)(2-\beta)-m \beta x)^{2}}{((2-\beta)(2+\beta(n-1)))^{2}}
\end{gathered}
$$

Consider the case where the innovator wants to elicit the adoption of the new innovation by exactly $m$ manufacturers. Than, the payoffs of the $m^{\text {th }}$ downstream firm are:

$$
\pi_{m}= \begin{cases}\frac{((a-c)(2-\beta)+(2+\beta(n-m-1)))^{2}}{((2-\beta)(2+\beta(n-1)))^{2}}-F(x) & \text { if } \quad m \in A \\ \frac{((a-c)(2-\beta)-(m-1) \beta x)^{2}}{((2-\beta)(2+\beta(n-1)))^{2}} & \text { if } \quad m \in B\end{cases}
$$

The sufficient condition for $m$ to be a stable equilibrium is:

$$
F \leq \frac{x(2+\beta(n-2))((a-c)(2-\beta)+(2+\beta(n-2 m)) x)}{((2-\beta)(2+\beta(n-1)))^{2}}
$$

Eq. (39) is the Participation Constraint of the innovator's maximization problem, which can be written as:

$$
\begin{gathered}
\max _{x ; m} \pi^{u}=m F-\gamma x^{2} \\
\text { s.t. } F \leq \frac{x(2+\beta(n-2))((a-c)(2-\beta)+(2+\beta(n-2 m)) x)}{((2-\beta)(2+\beta(n-1)))^{2}}
\end{gathered}
$$

By embedding the Participation Constraint in the profit function of the innovator, 
it is possible to rewrite eq.(19) as:

$$
\max _{x ; m} \frac{m x(2+\beta(n-2))((a-c)(2-\beta)+(2+\beta(n-2 m)) x)}{((2-\beta)(2+\beta(n-1)))^{2}}-\gamma x^{2}
$$

from which we have:

$$
\begin{gathered}
m^{*}=\frac{2(2-\beta)^{2} \gamma(\beta(n-1)+2)^{2}}{(\beta(n-2)+2)(\beta n+2)} \\
x^{*}=\frac{2(a-c)(2-\beta)(\beta(n-2)+2)(\beta n+2)}{\beta\left(8(2-\beta)^{2} \gamma(\beta(n-1)+2)^{2}-n(\beta(n(\beta(n-2)+6)-8)+12)-8\right)-8}
\end{gathered}
$$

One can see that, by setting $\beta=1$, i.e., by considering identical products, we go back to the exact results as in Section 3.2.

The rest of the mathematical analysis follows accordingly. Unfortunately, the same procedure for k-drastic innovations does not yield tractable results for $x$ and $m$ and we can only derive the equilibrium values of the outcomes in the downstream subgame - i.e. the output level and the Participation constraint, given the size of innovation. However, if we set $\beta=1$ the partial results coincide with those obtained in eqs. (27)-(30).

Now, let us analyse the effect of competition - measured as product similarity on the size of innovation and the number of licensees in equilibrium, if we keep $n$ constant :

$$
\left.x_{\beta}^{\prime}\right|_{n=\bar{n}}>0 ;\left.\quad m_{\beta}^{\prime}\right|_{n=\bar{n}}<0 \quad \forall \beta \in(\underline{\beta}, 1]
$$

Similarly, if we hold the product differentiation parameter $\beta$ constant and look at the effects of the number of active firms:

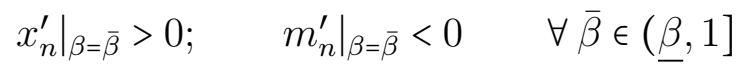

These results suggest that competition, either measured in terms of the number of active firms or the degree of product differentiation, has a negative impact on the diffusion of a superior technology. 


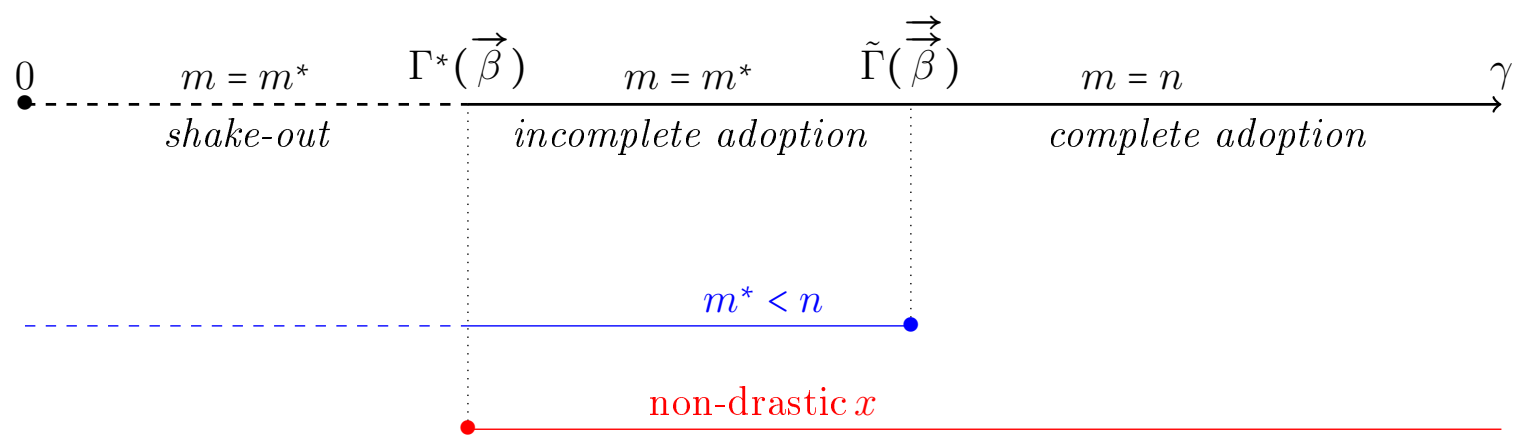

Figure 6: The effects of innovation on market structure, depending on the efficiency of the innovator $\gamma$.

Remark 3. The number of manufacturers that adopt the innovative technology is decreasing in the intensity of competition - either measured in terms of the number of active firms $n$, or the degree of product differentiation $\beta$ - and in the efficiency of the inventor, where:

$$
m= \begin{cases}m^{*} & \text { if } \quad \gamma<\frac{n(\beta(n-2)+2)(\beta n+2)}{2(2-\beta)^{2}(\beta(n-1)+2)^{2}} \equiv \tilde{\Gamma} \\ n & \text { otherwise }\end{cases}
$$

Finally, in order for the innovation to be non-drastic it must be that $m x \geq$ $\frac{(a-c)(2-\beta}{\beta}$. Using eqs. (42) and (43), we have that:

$$
m x \geq \frac{(a-c)(2-\beta)}{\beta} \quad \text { if } \quad \gamma<\frac{(\beta(n-2)+2)(\beta n+2)^{2}}{4(2-\beta)^{2} \beta(\beta(n-1)+2)^{2}} \equiv \Gamma^{*}
$$

With $\Gamma^{*}>\tilde{\Gamma} \forall \beta \in(\underline{\beta}, 1]$, and $\partial\left(\Gamma^{*}-\tilde{\Gamma}\right) /(\partial \beta)>0$, meaning that, as products become more substitute, it is easier to have k-drastic innovations and (even more) incomplete adoption of non-drastic ones. Figure 6 synthesises the results. 


\section{Appendix A.2}

\section{An alternative model of product differentiation}

Instead of $n$ firms competing on quantities for a homogeneous good, let us now assume that there are only two firms $\{i, j\}$ producing two differentiated products. There is a mass $\mu$ of consumers indexed by $y$ uniformly distributed on the unit interval (Figure 7). A consumer with a "low" $y$ prefers the brand produced by manufacturer $i$, while a consumer with a large $y$ prefers the brand produced by manufacturer $j$. The utility function of the consumer can be written as:

$$
U_{y} \stackrel{\text { def }}{=}\left\{\begin{array}{l}
a-p_{i}-t y \\
a-p_{j}-t(1-y)
\end{array}\right.
$$

where $a$ is the value the consumers assign to the final good, $p_{i}$ and $p_{j}$ are the prices of brand $i$ and $j$, respectively, and $t$ is the differentiation parameter: a low $t$ means that the two products are similar, while a high $t$ means that the two goods are very different in the eyes of the consumers. We assume the the two products are sufficiently differentiated, i.e., $t>\frac{\mu}{18 \gamma} \equiv \overline{\bar{t}}$

The two manufacturers can produce the final good either with a standard technology at a cost $c$ per unit, or with an innovative technology sold by an outside monopolist innovator at a price $F$. In this case, the firms lower their costs of production from $c$ to $c-x$ per unit, where $x$ represents the size of the cost-reducing effect. In order to develop the innovation, the innovator invests $I(x)=\gamma x^{2}$. The total cost function of the manufacturers can be written as:

$$
T C\left(q_{i}\right)= \begin{cases}c q_{i} & (\text { Standard }) \\ (c-x) q_{i}+F(x) & \text { (Innovative) }\end{cases}
$$

where $F(x)$ is the adoption fee, with $F(0)=0$. 


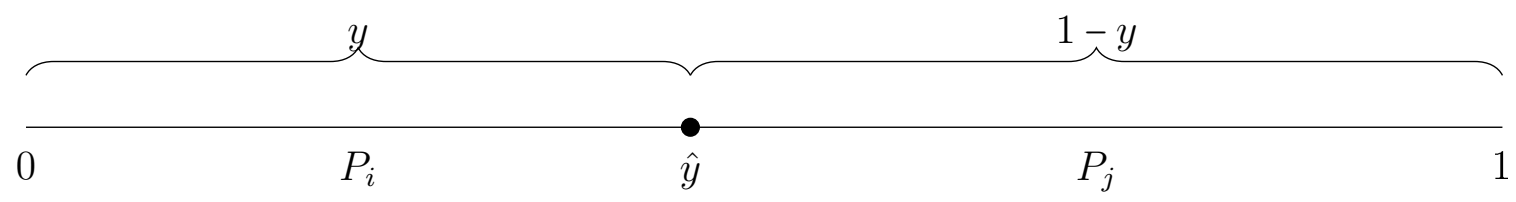

Figure 7: Holtelling's line: $\mu$ consumers indexed by $y$ on the unit interval with uniform density

I assume that all the firms can produce the output with the standard technology at no extra cost than the marginal ones. Following the standard procedure, we can find the position of the indifferent consumer on the unit interval. We index him/her with $\hat{y}$ :

$$
\hat{y}=\frac{p_{j}-p_{i}+t}{2 t}
$$

Now, we define the profit functions of the two manufacturers:

$$
\begin{gathered}
\pi_{i}=\mu \hat{y}\left(p_{i}-c+x_{i}\right)-F\left(x_{i}\right) \\
\pi_{j}=\mu(1-\hat{y})\left(p_{j}-c+x_{j}\right)-F\left(x_{j}\right)
\end{gathered}
$$

There are four possible scenarios: i) the two manufacturers decide to produce with the standard technology $\left(x_{i}=x_{j}=0\right)$; ii) the two manufacturers adopt the innovative technology $\left(x_{i}=x_{j}=x>0\right.$ ); iii) and iv) one firm (either $i$ or $j$ ) produces the good with the standard technology, while the rival adopts the innovative one $\left(x_{i} \neq x_{j}\right)$.

Solving the four scenarios, we obtain the following payoffs:

$$
\begin{array}{ll}
\pi(A, A)=\frac{\mu t}{2}-F ; & \pi(B, B)=\frac{\mu t}{2} \\
\pi(A, B)=\frac{\mu(3 t+x)^{2}}{18 t}-F ; & \pi(B, A)=\frac{\mu(3 t-x)^{2}}{18 t}
\end{array}
$$

with:

$$
\pi(A, B) \geq \pi(B, B)>\pi(A, A) \geq \pi(B, A)
$$

Matrix in Figure 1.5 shows eqs (1.21) and (1.21) in a normal-form game matrix. 


$$
\begin{array}{cc|c|c|}
\multicolumn{2}{c}{P_{j}} \\
\multicolumn{1}{c}{\mathrm{A}} & \multicolumn{1}{c}{\mathrm{B}} \\
\cline { 3 - 4 } P_{i} & \mathrm{~A} & \pi_{i}(A, A), \pi_{j}(A, A) & \pi_{i}(A, B), \pi_{j}(B, A) \\
\cline { 3 - 4 } & \mathrm{B} & \pi_{i}(B, A), \pi_{j}(A, B) & \pi_{i}(B, B), \pi_{j}(B, B) \\
\cline { 3 - 4 } & &
\end{array}
$$

Figure 8: Downstream manufacturers subgame. Strategy $\{A\}$ : adoption of the innovative technology. Strategy $\{\mathrm{B}\}$ : standard technology. Payoffs follow $\pi_{i}, \pi_{j}$.

The innovator sets a price that maximizes its profits. The licensing fee $F$ would be either the maximum fee that a manufacturer would pay in order to be the only adopter, or the maximum fee that elicits the adoption by the two manufacturers. In other words, depending on the innovator's interest between selling one contract or two, the price of the license would be equal to the difference between the gain from adoption minus the opportunity cost of adoption - i.e., the profits a manufacturer would obtain by deviating and producing with the standard technology.

$$
\begin{aligned}
& F(1)=\frac{\mu(3 t+x)^{2}}{18 t}-\frac{\mu t}{2}=\frac{\mu x(6 t+x)}{18 t} \\
& F(2)=\frac{\mu t}{2}-\frac{\mu(3 t-x)^{2}}{18 t}=\frac{\mu x(6 t-x)}{18 t}
\end{aligned}
$$

From this, we derive the optimal level of cost reducing innovation and the profits of the innovator in the two cases:

$$
x^{+}=\left\{\begin{array}{ll}
\frac{3 \mu t}{18 \gamma t-\mu} & \text { if one adopter only } \\
\frac{3 \mu t}{9 \gamma t+\mu} & \text { if two adopters }
\end{array} \quad \pi^{u}= \begin{cases}\frac{\mu^{2} t}{2(18 \gamma t-\mu)} & \text { if one adopter only } \\
\frac{\mu^{2} t}{9 \gamma t+\mu} & \text { if two adopters }\end{cases}\right.
$$

A simple comparison of the profits of the innovator gives us the following proposition:

Proposition 7. When competition is low - i.e, the two goods are sufficiently differentiated in the eyes of the consumers, $t>\mu / 9 \gamma$ - the innovator prefers providing the access of its technology to both firms in the downstream segment of the industry. Instead, when competition is intense - i.e., $t<\mu / 9 \gamma$ - then the innovator supplies 
the innovative input only to one manufacturer.

Proof. By comparing the profits of the innovator in case of one and two adopters, it is easy to observe that:

$$
\frac{\mu^{2} t}{2(18 \gamma t-\mu)}>\frac{\mu^{2} t}{9 \gamma t+\mu} \quad \text { if } \quad t<\frac{\mu}{9 \gamma}
$$

The result is comparable with the one derived in the main part of the article. In fact, tough competition - defined as either the number of firms producing the same good or, as in this case, the distance between the two products - decreases the number of licensees sold in equilibrium. This result may be explained following the usual Arrowian replacement effect. As the competition increases, the market power of the firms decreases and so does the rent generated by the innovation. This is particularly evident in this setting with product differentiation. When the products are similar, the price competition pushes the profits of the manufacturers to zero and the innovator can only extract low rents - if any. Therefore, by allowing one firm to access the new technological standard, the innovator is able to portion the market and take advantage from the asymmetry generated by the new technological endowment. In fact, as the adopter increases her share of the market, she also increases her market power and allows the innovator to extract a higher surplus.

\section{Appendix A.3}

\section{Equilibrium in mixed strategies}

Define $p$ as the probability that a firm adopts the new technology and $1-p$ as the probability of non-adoption. Then, the expected payoffs of the $m^{\text {th }}$ manufacturer are: 


$$
\begin{gathered}
\Pi(A)=-F+\sum_{j=0}^{n-1}\left(\begin{array}{c}
n-1 \\
j
\end{array}\right) p^{j}(1-p)^{n-1-j} \frac{(a-c+x(n-j))^{2}}{b(n+1)^{2}} \\
\Pi(B)=\sum_{j=0}^{n-1}\left(\begin{array}{c}
n-1 \\
j
\end{array}\right) p^{j}(1-p)^{n-1-j} \frac{(a-c-j x)^{2}}{b(n+1)^{2}}
\end{gathered}
$$

Where $j=m-1$. Using Binomial Theorem, eqs. (46) and (47) can be rewritten as:

$$
\begin{gathered}
\Pi(A)=-F+\frac{(a-c+x(n-(n-1) p))^{2}}{b(n+1)^{2}} \\
\Pi(B)=\frac{(a-c-(n-1) p x)^{2}}{b(n+1)^{2}}
\end{gathered}
$$

One can see that the $m^{\text {th }}$ firm chooses $A$ if and only if $\Pi(A) \geq \Pi(B)$. That is when:

$$
p(F) \leq \frac{n x(2(a-c)+n x)-b F(n+1)^{2}}{2(n-1) n x^{2}}
$$

Not surprisingly, the probability $p(F)$, that makes the $m^{\text {th }}$ manufacturer indifferent between either adopting the new technology $(\Pi(A))$ or producing with the standard one $(\Pi(B)$,$) falls when the price of that technology F$ increases. Moreover, one can see that $p(F)=0$ when $F \geq \bar{F} \equiv \frac{n x(2(a-c)+n x)}{b(n+1)^{2}}$, while $p(F)=1$ when $F \leq \check{F} \equiv \frac{n x(2(a-c)-(n-2) x)}{b(n+1)^{2}}$. In other words, when the price of the technology is high, the manufacturer is willing to pay the licensing fee if and only if few rivals, if any, adopt the new technology too - i.e., when the probability of adoption $p(F)$ is low. In fact, only when the adopters are very few, the gain from the new technology offsets the cost of adoption. As the price $F$ starts falling, the innovation becomes more attractive to several firms - i.e., the probability $p(F)$ increases.

Given the probability $p(F)$, it is now possible to write the expected profits of the supplier:

$$
\pi^{u}=-I(x)+\sum_{m=1}^{n}\left(\begin{array}{c}
n \\
m
\end{array}\right) p(F)^{m}(1-p(F))^{n-m} m F
$$


Again, by Binomial Theorem, eq.(49) can be rewritten as:

$$
\pi^{u}=-I(x)+[n p(F)] F
$$

The maximization of the innovator's profits w.r.t. the price of technology $F$ yields to:

$$
F=\frac{n x(2(a-c)+n x)}{2 b(n+1)^{2}}
$$

One can see that $F<\bar{F}$. Therefore, at least one firm is always willing to purchase the new technology and $p>0$. On the other hand, $F>\check{F}$ if $x>\frac{2(a-c)}{3 n-4}-$ i.e., when the innovation is sufficiently high, relatively to the competition level $n$. Finally, using eq.(50) in the profit function of the innovator and maximizing it w.r.t $x$, we obtain

$$
x^{*}=\frac{2 n^{3}(a-c)}{8 b \gamma(n-1)(n+1)^{2}-n^{4}}
$$

which leads to the probability of adoption:

$$
p^{*}=\frac{2 b \gamma(n+1)^{2}}{n^{3}}
$$

where $\gamma>\frac{3 n^{4}}{8 b(n-1)(n+1)^{2}}$, to guarantee that the innovation is non-drastic - i.e., $n x \leq(a-$ c). Define $\overline{\bar{N}}(n) \equiv n^{3} /(n+1)^{2}$, therefore, eq. $(52)$ can be rewritten as $p^{*}=2 b \gamma / \overline{\bar{N}}(n)$. Because $\overline{\bar{N}}(n)$ is a monotonic function of $\mathrm{n}$, with $\overline{\bar{N}}_{n}^{\prime}>0$, it is possible to state that an increase in competition implies a lower probability of adoption - i.e., $p_{n}^{\prime}<0$. From the results above, we confirm the results in Proposition 1 and Corollary 1:

Remark 4. The probability that a manufacturer adopts the innovative technology is 


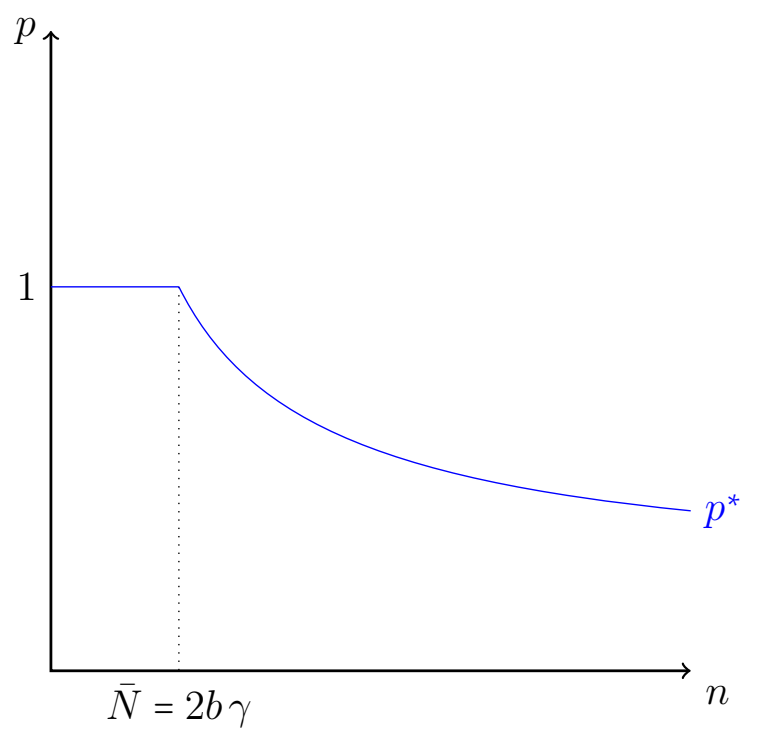

Figure 9: The probability of adoption $p$, depending on the number of active firms $n$. If $\overline{\bar{N}}(n)<2 b \gamma$, the number of licensees is $m^{*}=n$. Instead, if $\overline{\bar{N}}(n)>2 b \gamma$, the number of licensees is $m^{*}=n p^{*}$.

decreasing in the number of manufacturers ( $n)$, where:

$$
p= \begin{cases}p^{*} & \text { if } \quad \overline{\bar{N}}(n)>2 b \gamma \equiv \bar{N} \\ 1 & \text { otherwise }\end{cases}
$$

Remark 5. The average number of licensees elicited by the innovator is decreasing in the number of manufacturers ( $n)$, where:

$$
m= \begin{cases}n p^{*} & \text { if } \quad \overline{\bar{N}}(n)>2 b \gamma \equiv \bar{N} \\ n & \text { otherwise }\end{cases}
$$

Moreover, $\partial\left(n p^{*}\right) / \partial n<0$.

Using eq.(52) in the payoffs of the downstream manufacturers and the upstream inventor, it is possible to derive the equilibrium outcomes of the game, which are coherent with those derived in Section 3.2. Figure 9 shows Remark 4 graphically. 